\title{
Environment-dependent taste-aversion extinction: A question of stimulus novelty at conditioning
}

\author{
TREVOR ARCHER and PER-OLOW SJÖDÉN \\ Uppsala University, Uppsala, S-75106, Uppsala, Sweden
}

\begin{abstract}
In Experiment 1, four groups of rats were exposed to two saccharin(Sac)-lithium chloride(LiCl) pairings in a novel animal compartment. In subsequent daily extinction trials, Sac (two groups) or water $\left(\mathrm{H}_{2} \mathrm{O}\right)$ (two groups) was presented either in the same (as conditioning) or a different compartment. There was no evidence that the presence or absence of the conditioning compartment influenced the amounts of Sac or $\mathrm{H}_{2} \mathrm{O}$ drunk. Postextinction preference tests (Sac vs. $\mathrm{H}_{2} \mathrm{O}$ ), performed in the conditioning compartment, showed a compartment-dependent extinction effect: There was a significantly stronger aversion in the group drinking Sac during extinction in a different (from conditioning) compartment than in the group drinking Sac in the conditioning compartment. In Experiment 2, four groups were given two Sac-LiCl trials in a novel (2 groups) or a familiar (2 groups) compartment. One "novel compartment" group and one "familiar" group were offered Sac during daily Sac-aversion extinction trials in the conditioning compartment, and the remaining groups drank Sac in a different compartment. Again, intercompartment generalization of the Sac aversion was demonstrated: There was no evidence that the particular compartment present influenced the strength of aversion during extinction. Postextinction preference tests showed the previously observed compartment-dependent extinction effect only in the case of the "novel compartment" groups. Thus, in view of previously reported data, the number of conditioning trials and the novelty of the conditioning compartment were shown to be critical to compartment-dependent taste-aversion extinction.
\end{abstract}

There has been widespread interest in food-aversion learning during the last two decades (Barker, Best, \& Domjan, 1977; Milgram, Krames, \& Alloway, 1977). An early impetus for this direction of research was the fact that food-aversion learning seemed to contradict traditional conceptions of basic learning processes (Rozin \& Kalat, 1971; Seligman, 1970; Seligman \& Hager, 1972; Shettleworth, 1973). However, recent reviews of the available literature (Dickinson \& Mackintosh, 1978; Logue, 1979) have reached the conclusion that only parametric differences exist between food-aversion learning and other learning paradigms, and that no special principles are required to account for data on food-aversion learning (Logue, 1979).

One of the supposedly unique characteristics initially attributed to food-aversion learning in rats was its alleged independence of exteroceptive stimulation (Garcia, Hankins, \& Rusiniak, 1974; Revusky \& Garcia, 1970). Thus, it was demonstrated that rats learn to avoid a taste component, but not a visualauditory component, of a compound stimulus paired

Thanks are due to Gurra Ohlin for competent laboratory assistance. The present research was supported by Grants $963 / 78$ and 584/79 to Per-Olow Sjödén from the Swedish Council for Research in the Humanities and Social Sciences. Request reprints from Per-Olow Sjödén, Department of Applied Psychology, Uppsala University, Box 468, S-751 06, Uppsala, Sweden. T. Archer's present address is Astra Chemicals, S-15185, Södertälje, Sweden. with illness (Garcia \& Koelling, 1966). Furthermore, it was shown that the visual-auditory component, but not the taste component, became aversive after pairing with electric shock (Garcia \& Koelling, 1966). These and other similar findings (Domjan \& Wilson, 1972; Garcia, Kimeldorf, \& Hunt, 1961) inspired the notions that rats "tend to ignore external events" (Revusky \& Garcia, 1970, p. 22), that "time-space contextual information ... is dispensed with as unnecessary" (Garcia et al., 1974, p. 828) in the food-aversion learning situation, and that food aversion learning, in contrast with, for example, shock avoidance learning, generalizes readily to a new environment (Kalat, 1977; see also Garcia, Kovner, \& Green, 1970).

In contrast with the above notion, recent evidence that demonstrates aversions to exteroceptive stimuli has been collected (Best, Best, \& Mickley, 1973; Mitchell, Kirschbaum, \& Perry, 1975; Morrison \& Collyer, 1974). Also, the importance of exteroceptive stimulation for taste- and illness-familiarity effects in taste-aversion learning has been demonstrated (Rudy, Iwens, \& Best, 1977; Rudy, Rosenberg, \& Sandell, 1977).

In a recent study (Archer, Sjödén, Nilsson, \& Carter, 1979), we presented a compound stimulus consisting of a novel taste and a novel set of exteroceptive stimuli (odor, cage, and bottle) at conditioning, poisoned the animals, and tested for variations in the strengths of the resulting taste aversions in the presence or absence of the exteroceptive conditioning elements. 
A change of exteroceptive context from conditioning to extinction resulted in a higher absolute intake of the taste substance than when the conditioning context was maintained. This we refer to as a context-dependent conditioning effect. Also, postextinction saccharin preference tests performed in the conditioning and extinction contexts showed that groups given extinction trials in an exteroceptive context different from that of conditioning retained their saccharin aversion in the conditioning context only. This we term a contextdependent extinction effect. In further studies (Archer, Sjödén, Nilsson, \& Carter, 1980), we have shown that the odor component was of no importance in producing the above effects and that the particular drinking bottle exerted the major part of the exteroceptive control of taste aversion. In addition, we found that tongue-tactile stimuli from the drinking bottle, present at conditioning, exerted significant control over subsequent intake of the taste substance (Archer, Sjödén, $\&$ Carter, 1979). These findings are in agreement with results obtained by other workers, demonstrating that rats can form an aversion to specific tonguetactile cues after only a few contingent lithium chloride (LiCl) injections (Nachman, Rauschenberger, \& Ashe, 1977).

The present study was an attempt to investigate context-dependent effects in taste-aversion learning by varying the specific animal compartment present at saccharin-aversion conditioning and extinction. A successful demonstration of such effects would seriously question the notion that taste aversions, in contrast with other kinds of learning, generalized readily between exteroceptive contexts (e.g., Kalat, 1977). In a previous study, we had failed to find evidence of exteroceptive control over postconditioning saccharin intake exerted by the conditioning compartment (Archer, Sjödén, \& Carter, 1979). The present study differed from the previous one in that two conditioning trials were used instead of one. Moreover, in Experiment 1, an attempt was made to study whether or not the demonstration of exteroceptive control over fluid intake was dependent on the presence of the taste CS, as found in a previous study (Archer et al., 1980). In Experiment 2, we varied the relative novelty of the animal compartment at conditioning in order to assess its role in the establishment of control over learned taste aversion. Previous data had suggested (Archer \& Sjödén, 1979a, 1979b, 1980) that a lesser degree of exteroceptive control results when the exteroceptive compound is familiar at conditioning than when it is novel.

\section{EXPERIMENT 1}

Two saccharin(CS)-LiCl(UCS) pairings were administered to four groups of rats in the presence of a novel, distinctive animal compartment. During a subsequent extinction phase, saccharin was presented to two groups, either in the same compartment as during conditioning (Group SS = same, saccharin) or in a different environment (Group DS = different, saccharin). Two groups were offered water in the same (Group SW = same, water) or in a different (Group $\mathrm{DW}=$ different, water) environmental context. The latter two groups were included to investigate whether exteroceptive control of postconditioning fluid intake was dependent on the presence of the taste stimulus, as found in a previous study (Archer et al., 1980). In that study, a compound consisting of compartment and bottle elements was demonstrated to control postconditioning fluid intake only in the presence of the taste stimulus.

Postextinction saccharin preference tests were performed in the conditioning environment for all groups. Exteroceptive contextual control over fluid intake should be evidenced by a lower intake in Group SS than in Group DS during extinction, and by lower saccharin preference values in Group DS than in Group SS after the extinction phase.

\section{Method}

\section{Animals}

Twenty-four experimentally naive male Sprague-Dawley rats (AB Anticimex, Sollentuna, Sweden), weighing between 200 and $250 \mathrm{~g}$ at the beginning of the experiment, were assigned to four groups $(n=6)$ matched for body weight.

\section{Apparatus}

Two types of housing conditions were employed: (1) a normal condition, consisting of individual Perspex cages $(16.5 \times 22.5 \times$ $13.5 \mathrm{~cm}$ ), with gridded metal covers with spaces for food and water bottle, and (2) a contextual condition, consisting of individual compartments $(15 \times 35 \times 20 \mathrm{~cm})$, opaque plastic boxes with light excluded by Masonite covers except for two holes for the drinking bottles. Food pellets were placed on the floor of the compartments. Throughout the experiment, food (lab chow R3, Astra-Ewos, Södertälje, Sweden) was available ad lib, and drinking fluids were always presented in 250-ml plastic bottles (Techniplast, Italy) with metal nozzles that had a $6-\mathrm{mm}$ hole at the tip. The nozzle contained a small metal ball which created a considerable amount of noise when the animals licked its top.

\section{Procedure}

The animals were kept on a 12-h-on/12-h-off lighting schedule (lights on at $0800 \mathrm{~h}$ ) in a room thermostatically maintained between $21^{\circ}$ and $23^{\circ} \mathrm{C}$. All animals were given an equal amount of handling each day.

Preconditioning. The animals were housed in the normal condition cages, and water was presented freely during a 2-week acclimatization period. Following this, water access was limited during a 4-day period, first to $1 \mathrm{~h} /$ day and then to $30 \mathrm{~min} /$ day. All subsequent fluid presentations, except for preference tests, took place between 0800 and $0830 \mathrm{~h}$. All compartment changes were performed immediately before the fluid presentations in all subsequent phases and experiments.

Conditioning. Experimental conditions and treatments are outlined in Table 1. The experimental manipulations were carried out on odd-numbered days, with a day of 30 min of water drinking on the days in between (even-numbered days).

On Day 1 (conditioning), all animals were placed in the contextual condition cage and were offered a $.2 \%$ saccharin solution for $30 \mathrm{~min}$. Approximately $15 \mathrm{~min}$ after termination of the drinking period, all animals were given a $2.5-\mathrm{ml} .15-\mathrm{M} \mathrm{LiCl}$ injection (ip) 
Table 1

Experimental Manipulations and Chronology

\begin{tabular}{|c|c|c|c|}
\hline Group & $\begin{array}{l}\text { Conditioning } \\
\text { (Days } 1 \text { and 3) }\end{array}$ & $\begin{array}{c}\text { Extinction } \\
\text { (Days } 5,7,9,11, \text { and 13) }\end{array}$ & $\begin{array}{l}\text { Preference Tests } \\
\text { (Days } 15 \text { and 17) }\end{array}$ \\
\hline \multicolumn{4}{|c|}{ Experiment 1} \\
\hline $\begin{array}{l}\text { SS } \\
\text { DS } \\
\text { SW } \\
\text { DW }\end{array}$ & $\begin{array}{l}\text { Contextual, Saccharin + LiCl } \\
\text { Contextual, Saccharin + LiCl } \\
\text { Contextual, Saccharin + LiCl } \\
\text { Contextual, Saccharin + LiCl }\end{array}$ & $\begin{array}{l}\text { Contextual, Saccharin } \\
\text { Normal, Saccharin } \\
\text { Contextual, Water } \\
\text { Normal, Water }\end{array}$ & $\begin{array}{l}\text { Contextual } \\
\text { Contextual } \\
\text { Contextual } \\
\text { Contextual }\end{array}$ \\
\hline \multicolumn{4}{|c|}{ Experiment 2} \\
\hline $\begin{array}{l}\text { N-SS } \\
\text { N-DS } \\
\text { F-SS } \\
\text { F-DS }\end{array}$ & $\begin{array}{l}\text { Contextual, Saccharin }+\mathrm{LiCl} \\
\text { Contextual, Saccharin }+\mathrm{LiCl} \\
\text { Normal, Saccharin + LiCl } \\
\text { Normal, Saccharin + LiCl }\end{array}$ & $\begin{array}{l}\text { Contextual, Saccharin } \\
\text { Normal, Saccharin } \\
\text { Normal, Saccharin } \\
\text { Contextual, Saccharin }\end{array}$ & $\begin{array}{l}\text { Contextual } \\
\text { Contextual } \\
\text { Normal } \\
\text { Normal }\end{array}$ \\
\hline
\end{tabular}

Note-Contextual $=$ contextual condition; normal $=$ normal condition. The following abbreviations are employed for denoting groups: $N-=$ novel exteroceptive context at conditioning; $F-=$ familiar exteroceptive context at conditioning (all groups in Experiment 1 were placed in a novel conditioning context); first $S=$ conditioning and extinction contexts the same; $D=$ extinction context different from conditioning context; second $S=$ saccharin during extinction phase; $W=$ water during extinction phase.

and then immediately replaced in the contextual condition cages. They remained there until Day 2, when they were returned to the normal condition cages for a 30-min water-drinking period. They were left there until Day 3, when a second conditioning trial identical to that of Day 1 was administered.

Extinction. On Day 5 (Extinction 1: E1), Groups SS and SW were placed in the same environment as during conditioningthe contextual condition-while Groups DS and DW were handled and remained in the normal condition. Groups SS and DS were offered saccharin for $30 \mathrm{~min}$, while Groups SW and DW were offered water. All animals remained in their respective environmental conditions until Day 6, when Groups SS and SW were returned to the normal condition and Groups DS and DW were handled only. Water was then presented for $30 \mathrm{~min}$, after which all groups remained in the normal condition. Identical contextual or normal placements and saccharin or water presentations were made on Days 7, 9,11, and 13 (E2-E5), and water presentations, in the normal condition, were made to all groups on Days 8, 10, 12, and 14.

Preference testing. On Day 15 (Test 1: T1), all animals were placed in the contextual condition, in which they remained during preference testing. They were given an 8 -h saccharin preference test $(0800$ to $1600 \mathrm{~h})$, with each animal receiving one saccharin bottle $(.2 \%)$ and one water bottle. An in-between day of water drinking intervened on Day 16. A second preference test (T2) followed on Day 17; this test was identical to the first, except that the positions of the fluid bottles were reversed. The percent preference for saccharin in relation to total fluid intake was computed. Throughout, fluid intake was recorded by weighing the bottles to the nearest $1.0 \mathrm{~g}$.

\section{Results and Discussion}

All data were subjected to analysis of variance (Kirk, 1968), based on split-plot designs and using $\mathrm{p}<.05$ throughout. Pairwise comparisons were performed with the Tukey HSD test (Kirk, 1968).

The data from the conditioning trials indicate that saccharin aversions were reliably produced in all groups. There was a significant effect of Days $[F(1,20)$ $=334.3]$ due to the following pattern of mean saccharin intake values: Day 1 = Groups SS, $16.3 \mathrm{~g}$; DS, $15.7 \mathrm{~g}$; SW, $13.3 \mathrm{~g}$; and DW, $14.5 \mathrm{~g}$. Day $3=$ Groups SS, 7.2 g; DS, $6.7 \mathrm{~g}$; SW, $4.8 \mathrm{~g}$, and DW, $5.8 \mathrm{~g}$. Pairwise comparisons between groups within days and within groups between days indicated signif- icant decreases of saccharin intake between days in all groups.

The data from the extinction phase (E1-E5) are presented in Figure 1 (left-hand panel). There was no evidence that the presence (Groups SS and SW) or absence (Groups DS and DW) of the conditioning environment influenced the amount of fluid drunk during extinction. Thus, there were no differences between Group SS and Group DS, on the one hand, or between Group SW and Group DW, on the other. However, there was a Groups by Days interaction $[F(12,80)=12.9]$ due to a significantly lower fluid intake by the saccharin-drinking groups (SS and DS) than by the water-drinking groups (SW and DW) on

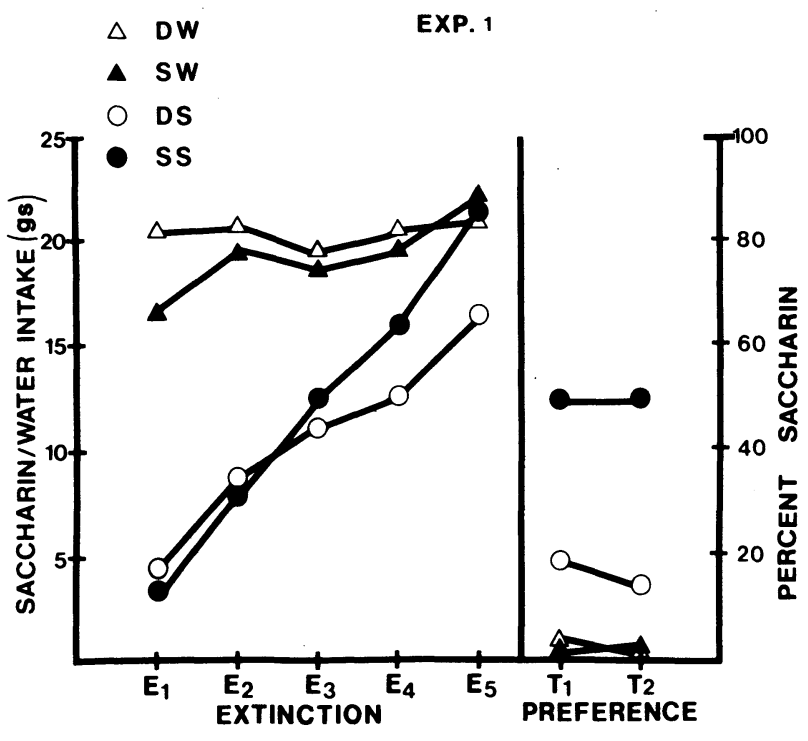

Figure 1. Saccharin or water intake during extinction and percent saccharin intake during preference tests by four groups of rats in Experiment 1. DW = different (from conditioning) context, water presented; SW = same (as conditioning) context, water presented; DS = different context, saccharin presented; SS = same context, saccharin presented. 
E1 and E2 $(p<.01)$. Also, Group DS drank less saccharin than Groups SW and DW on E3 and E4. Comparisons of the intake on E1 with that on E5 revealed significant increases in all groups except DW $(p<.01)$. Since there were no differences between the "same" and "different" groups, the data do not indicate a context-dependent conditioning effect. Thus, the saccharin aversion generalized readily between the contextual and normal conditions.

The preference test data are illustrated in Figure 1 (right-hand panel). The prediction that Group DS would show lower saccharin preference values than Group SS after extinction was confirmed. There was a significant Groups effect $[F(3,20)=15.8]$ due to the fact that Groups SW and DW, as well as Group DS, showed significantly more taste aversion on both tests than Group SS $(p<.01)$. These data indicate that when saccharin is consumed without subsequent poisoning in an animal compartment different from that present at conditioning (Group DS), the saccharin aversion in the conditioning compartment remains virtually intact. We therefore conclude that a contextdependent extinction effect was demonstrated. The fact that water drinking in the conditioning environment was not shown to weaken the subsequent saccharin aversion (Group SW) may be due to a "floor effect," since the taste aversion per se was very strong in the water groups at T1 and T2. The latter finding parallels previous results (Archer et al., 1980, Experiment 3).

It may be argued that the fact that there were significant $S<D$ effects during the two-bottle preference tests but not during the 30-min one-bottle extinction tests is due to the greater sensitivity of the former test as compared with the latter (Grote \& Brown, 1971). However, the one-bottle test is sensitive enough to have detected the presence or absence of an exteroceptive conditioning compound, consisting of cage, bottle, and odor (Archer, Sjödén, Nilsson, \& Carter, 1979), cage and bottle (Archer et al., 1980), and bottle elements alone (Archer, Sjödén, \& Carter, 1979), in previous studies. We therefore prefer not to attribute the pattern of results obtained here entirely to the differential sensitivity of the two types of test.

\section{EXPERIMENT 2}

We have previously shown that the relative novelty of the exteroceptive conditioning context greatly influences its ability to control subsequent intake of the taste substance. Thus, we have demonstrated: (1) that the greater the number of novel exteroceptive components included in the compound presented at conditioning, (a) the greater the suppression of saccharin intake (neophobia) on the conditioning trial and (b) the lower the absolute intake of saccharin by the "same" context groups on the first extinction trial
(Archer \& Sjödén, 1979a, 1979b); and (2) that lesser exteroceptive control over postconditioning saccharin intake results when the exteroceptive compound is familiar at conditioning than when it is novel (Archer \& Sjödén, 1980). These results were obtained both with a cage + bottle + odor compound and with a cage + bottle compound (Sjödén \& Archer, Note 1).

In Experiment 2, we included two groups identical to Groups SS and DS in an effort to replicate the findings of Experiment 1. These groups were labeled N-SS and N-DS $(\mathrm{N}=$ novel $)$ in order to indicate that the exteroceptive context was novel at conditioning and to distinguish them from Groups F-SS and F-DS $(\mathrm{F}=$ familiar), to which the exteroceptive conditioning context was familiar. On the basis of previous findings, the novelty/familiarity manipulation on the conditioning trial should result in the following differences: (1) There should be a lesser intake of saccharin (i.e., a stronger neophobia) in Groups N-SS and N-DS than in Groups F-SS and F-DS at conditioning; (2) the $\mathrm{N}$-SS $<\mathrm{N}$-DS difference of absolute saccharin intake during extinction should be greater than the F-SS < F-DS difference; (3) when postextinction preference testing is performed in the original conditioning compartment, we expect the N-DS $<\mathrm{N}$-SS difference to be larger than the F-DS < F-SS difference.

\section{Method}

With the exceptions noted below, the general method of Experiment 1 was maintained. Experimental treatments are described in Table 1.

Twenty-four male Sprague-Dawley rats were assigned to four groups $(n=6)$. After the acclimatization period and a 4-day period of adjustment to a schedule of limited access to water, a first taste-aversion conditioning trial was administered on Day 1. Groups N-SS and N-DS were first moved (from the normal condition) to the novel contextual condition, while Groups F-SS and F-DS remained in the normal condition. All animals were then offered saccharin for $\mathbf{3 0} \mathrm{min}$ and then given a $\mathrm{LiCl}$ injection approximately 15 min after the end of the drinking period. Groups N-SS and $\mathrm{N}$-DS were then replaced in the contextual condition and Groups F-SS and F-DS were replaced in the normal condition. After a 30-min period of water drinking with all groups in the normal condition on Day 2, a second conditioning trial, identical to the first, was administered on Day 3. The extinction phase begun on Day 5 (E1), with Groups N-SS and F-DS in the contextual condition and Groups N-DS and F-SS in the normal condition. All animals were offered saccharin for $30 \mathrm{~min}$. Identical extinction trials (E2-E5) were given on Days 7, 9, 11, and 13, with water-drinking sessions in the normal condition interspersed on the days in between. On Day 15, Groups N-SS and N-DS were placed in the contextual condition, while Groups F-SS and F-DS remained in the normal condition. Saccharin preference was then assessed as in Experiment 1 (T1). After a day of 30-min water drinking on Day 16, a second preference test (T2) followed on Day 17.

\section{Results and Discussion}

The conditioning data indicate that taste aversions were formed in all groups. Thus, there was a significant Days effect $[F(1,20)=111.5]$ for saccharin in- 


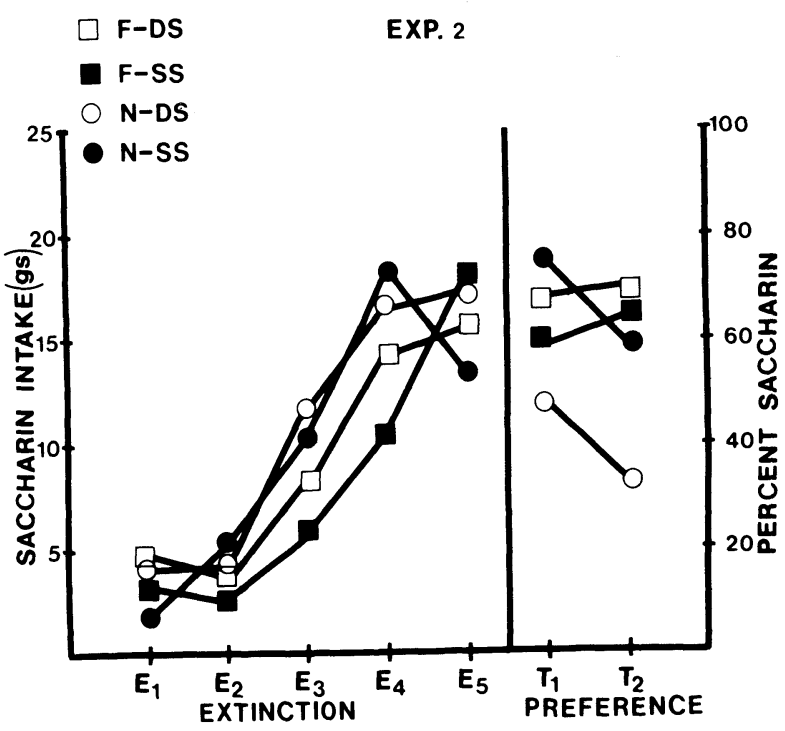

Figure 2. Saccharin intake during extinction and percent saccharin intake during preference tests by four groups of rats in Experiment 2. F-DS = familiar conditioning context, different (from conditioning) context during extinction; F-SS = familiar context, same (as conditioning) context during extinction; $\mathbf{N}$-DS = novel context, different context during extinction; and $\mathbf{N}-\mathrm{SS}=$ novel context, same context during extinction. Saccharin was offered to all groups during the extinction phase.

take, and the mean values were: Day $1=$ Groups N-SS, $12.3 \mathrm{~g}$; N-DS, $13.2 \mathrm{~g}$; F-SS, $12.8 \mathrm{~g}$; F-DS, $11.3 \mathrm{~g}$; and Day 3 = N-SS, 4.2 g; N-DS, 4.5 g; F-SS, $4.8 \mathrm{~g}$; and F-DS, $3.7 \mathrm{~g}$. There were no indications that the presentation of saccharin to the $\mathrm{N}$ groups in a novel animal compartment suppressed saccharin intake more than did the presentation of saccharin to the $F$ groups in the familiar home cages. Thus, in contrast with the case in which either novel compartments and drinking bottles (Sjödén \& Archer, Note 1) or novel compartments, bottles, and an odor (Archer \& Sjödén, 1980) were introduced at the conditioning trial, there seems to be no neophobic reaction to the novel compartment alone.

The extinction data failed to confirm our prediction that there would be a greater $S<D$ difference of absolute intake of saccharin in the $\mathbf{N}$ groups than in the $F$ groups. In fact, there was no evidence of a context-dependent conditioning effect. These data are presented in Figure 2 (left-hand panel), and analysis of variance indicated a Groups by Days interaction $[\mathrm{F}(12,80)=2.8]$. However, subsequent pairwise comparisons revealed no significant differences between the groups. All groups showed an increase of saccharin intake from $E 1$ to $E 5(p<.01)$.

The preference-test data are presented in Figure 2 (right-hand panel). There was a clear indication of a large and statistically significant difference between Groups N-SS and N-DS, but not between Groups F-SS and F-DS. Thus, the relative novelty of the conditioning context determined whether or not a context- dependent extinction effect would show up in the preference-test data. The analysis of variance yielded a Groups effect $[F(3,20)=4.9]$, and HSD testing for pairwise differences between groups over both tests revealed that Group N-DS showed significantly ( $p<$ $.05)$ lower saccharin-preference values than Groups N-SS and F-SS. These data confirm the results from the corresponding DS and SS groups of Experiment 1.

\section{GENERAL DISCUSSION}

In a previous experiment (Archer et al., 1979a, Experiment 1) utilizing the same general paradigm as in the present cases, but with only one taste-aversion conditioning trial, we found neither a context-dependent conditioning effect (as measured during the extinction phase) nor a context-dependent extinction effect (as measured during preference testing). In the present experiments, in which two trials were given, a contextdependent extinction effect was demonstrated in the preference-test data, although no context-dependent conditioning effect was observed. Thus, there was substantial between-compartment generalization of the saccharin aversion immediately after conditioning. However, the preference-test data do suggest that rats learn about the specific animal compartment in which a learned taste-aversion is extinguished, at least when two trials are employed. Thus, we may conclude that the animals learn during extinction that "saccharin is no longer aversive in the extinction compartment," an experience which leaves the aversiveness of saccharin in the conditioning compartment virtually intact, provided that the conditioning and extinction compartments are different.

The extinction-phase data failed to provide any evidence for a context-dependent conditioning effect, since there was no effect of "same" vs. "different" compartments during this phase. In contrast with previous studies, in which a cage + bottle + odor compound (Archer, Sjödén, Nilsson, \& Carter, 1979), a cage + bottle compound (Archer et al., 1980), and bottle stimuli alone (Archer, Sjödén, \& Carter, 1979) resulted in context-dependent conditioning effects, the present finding does not allow a differentiation between two accounts of what the animals learn at conditioning: whether they learn that "saccharin is aversive in all types of compartments" or that "saccharin is aversive in the conditioning compartment only." The lack of significant "same" < "different" effects during extinction suggests that the former account is the most accurate when animal compartments only are manipulated. Thus, the notion that taste aversions generalize readily to a new animal compartment (Kalat, 1977) is supported by the present extinction data, but contradicted by the demonstration of a clear contextdependent extinction effect in the preference-test data. However, in a recent study (Sjödén \& Archer, Note 1), 
we established a saccharin aversion in the presence of a novel compartment + bottle context, and extinguished it (1) in the same context as that present at conditioning, (2) in a previously familiar cage + bottle context, or (3) in a completely unfamiliar cage where saccharin was available in a drinking cup. The data supported the notion that the animals learn at conditioning that "saccharin is aversive in the conditioning context only," since the extinction curves for the last two conditions were identical and much steeper than that for the first condition. Thus, rats seem to learn that "saccharin is aversive in the conditioning bottle only," but not that "saccharin is aversive in the conditioning compartment only" in the taste-aversion learning paradigm.

By varying the relative novelty of the conditioning compartments, we found that when taste-aversion conditioning took place in a familiar compartment, there was neither a context-dependent conditioning effect nor an extinction effect. This suggests that what takes place during conditioning differentially affects subsequent learning about the generality of the saccharin aversion across environmental conditions. On the basis of previous findings, we have suggested that the control of subsequent saccharin intake exerted by a familiar exteroceptive conditioning compound, consisting of compartment, bottle, and odor elements (Archer \& Sjödén, 1980) or of compartment and bottle elements (Sjödén \& Archer, Note 1), is much less than that exerted by a novel conditioning compound with the same elements. The present data are consistent with our earlier suggestion that rats learn about the exteroceptive context on a taste-aversion conditioning trial, provided that at least some exteroceptive elements change when the taste substance is first introduced. Therefore, the reason there was no difference between Groups F-SS and F-DS on the preference tests in Experiment 2 is that, as indicated by the lack of evidence, these groups did not learn anything about the specific conditioning compartment in the first place. Thus, extinguishing the aversion in a different (from conditioning) compartment resulted only in saccharin per se losing its aversive properties in all contexts.

In Experiment 2, there was neither a measurable neophobia effect of the novel compartments on the conditioning trial nor any indication of a contextdependent conditioning effect in the extinction data. This correlation of the magnitude of the conditioning trial neophobia with the magnitude of the contextdependent conditioning effect, also attested to in our previous studies, supports the two-process theory advanced by Mitchell and his co-workers (e.g., Mitchell, Parker, \& Johnson, 1976). According to this theory, an associative CS-UCS component is superimposed upon a neophobic response to the taste + exteroceptive context in taste-aversion learning.

It has been proposed that contextual background stimuli present at conditioning in appetitive (e.g.,
Sheafor, 1975) and aversively motivated paradigms (e.g., McAllister \& McAllister, 1971) enters into the associative relationships established. Therefore, a generalization decrement should occur if the background stimuli are allowed to vary between, for example, conditioning and a subsequent extinction phase. The present experiments were based on this assumption. By varying apparatus (McAllister \& McAllister, 1963) and extraapparatus background stimuli (McAllister \& McAllister, 1965) between shock-based fear conditioning and later hurdle-jumping escape responding, such a generalization decrement had been demonstrated. It may be hazardous to compare such data with our results on context dependence of conditioned taste aversions, due to differences in the relative sensitivity of response measures, differences in the number and kinds of stimuli that are allowed to vary, etc. Still, it should be noted that, when a compound of cage + bottle + odor stimuli is allowed to differ between conditioning and extinction of a taste aversion (Archer, Sjödén, Nilsson, \& Carter, 1979), the generalization decrement is of the same relative magnitude as that when apparatus cues are varied in avoidance conditioning (McAllister \& McAllister, 1963, 1965). When fewer compound elements are allowed to vary between conditions (cage + bottle: Archer, Sjödén, \& Carter, 1979; bottle: Archer et al., 1980), however, a much smaller decrement occurs. In the present study, in which cage stimuli alone were varied, no generalization decrement occurred during extinction. Thus, it seems as if the number and kinds of conditioning compound elements are strong determinants of the extent of contextual control over conditioned taste aversions.

\section{REFERENCE NOTE}

1. Sjödén, P. O., \& Archer, T. Associative and non-associative effects of exteroceptive context in taste-aversion conditioning with rats. Manuscript submitted for publication, 1980.

\section{REFERENCES}

Archer, T., \& SJödÉn, P. O. Neophobia in taste-aversion conditioning: Individual differences and effects of contextual changes. Physiological Psychology, 1979, 7, 364-369. (a)

Archer, T., \& SuödÉn, P. O. Positive correlation between preand postconditioning saccharin intake in taste-aversion learning. Animal Learning \& Behavior, 1979, 7, 144-148. (b)

Archer, T., \& SuödÉn, P. O. Context-dependent taste-aversion learning with a familiar conditioning context. Physiological Psychology, 1980, 8, 40-46.

Archer, T., Suödén, P. O., \& Carter, N. Control of tasteaversion extinction by exteroceptive cues. Behavioral and Neural Biology, 1979, 25, 217-226.

Archer T., Suödén, P. O., Nilsson, L.-G., \& Carter, N. Role of exteroceptive background context in taste-aversion conditioning and extinction. Animal Learning \& Behavior, 1979, 7, 17-22.

Archer, T., Suödén, P. O., Nilsson, L.-G., \& Carter, N. Exteroceptive context in taste-aversion conditioning and extinction: Odour, cage, and bottle stimuli. Quarterly Journal of Experimental Psychology, 1980, 32, 197-214. 
Barker, L. M., Best, M. R., \& Domjan, M. Learning mechanisms in food selection. Waco, Tex: Baylor University Press, 1977.

Best, P. J., Best, M. R., \& Mickley, G. A. Conditioned aversion to distinct environmental stimuli resulting from gastrointestinal distress. Journal of Comparative and Physiological Psychology, 1973, 85, 250-257.

Dickinson, A., \& Mackintosh, N. J. Classical conditioning in animals. Annual Review of Psychology, 1978, 29, 587-612.

Domjan, M., \& Wilson, N. E. Specificity of cue to consequence in aversion learning in the rat. Psychonomic Science, 1972, 26, 143-145.

Garcia, J., Hankins, W. G., \& Rusiniak, K. W. Behavioral regulation of the milieu interne in man and rat. Science, 1974, $185,823-831$.

Garcia, J., Kimeldorf, D. J., \& Hunt, E. L. The use of ionizing radiation as a motivating stimulus. Psychological Review, 1961, 68, 383-395.

Garcia, J., \& Koelling, R. A. Relation of cue to consequence in avoidance learning. Psychonomic Science, 1966, 4, 123-124.

Garcia, J., Kovner, R., \& Green, K. F. Cue properties vs palatability of flavors in avoidance learning. Psychonomic Science, 1970, 20, 313-314.

Grote, F. W., JR., \& Brown, R. T. Conditioned taste aversions: Two-stimulus tests are more sensitive than one-stimulus tests. Behavior Research Methods \& Instrumentation, 1971, 3, 311-312.

KALAT, J. W. Biological significance of food aversion learning. In N. W. Milgram, L. Krames, \& T. M. Alloway (Eds.), Food aversion learning. New York: Plenum Press, 1977.

KIRK, R. E. Experimental design: Procedures for the behavioral sciences. Belmont, Calif: Brooks/Cole, 1968.

LOGUE, A. W. Taste aversion and the generality of the laws of learning. Psychological Bulletin, 1979, 86, 276-296.

MCAlliste R, W. R., \& McAlliste r, D. E. Increase over time in the stimulus generalization of acquired fear. Journal of Experimental Psychology, 1963, 65, 576-582.

McAllister, W. R., \& McAllister, D. E. Variables influencing the conditioning and the measurement of acquired fear. In W. F. Prokasy (Ed.), Classical conditioning: $A$ symposium. New York: Appleton-Century-Crofts, 1965.

McAlliste R, W. R., \& MCAlliste R, D. E. Behavioral measurement of conditioned fear. In F. R. Brush (Ed.), Aversive conditioning and learning. New York: Academic Press, 1971.

Milgram, N. W., Krames, L., \& Alloway, T. M. Food aversion learning. New York: Plenum Press, 1977.

Mitchell, D., Kirschbaum, E. H., \& Perry, R. L. Effects of neophobia and habituation on the poison-induced avoidance of exteroceptive stimuli in the rat. Journal of Experimental Psychology: Animal Behavior Processes, 1975, 104, 47-55.

Mitchell, D., Parker, L. F., \& Johnson, R. Absence of a generalization decrement in the poison-induced avoidance of exteroceptive stimuli in the rat. Physiological Psychology, 1976, 4, 121-123.

Morrison, G. R., \& Collyer, R. Taste-mediated conditioned aversion to an exteroceptive stimulus following $\mathrm{LiCl}$ poisoning. Journal of Comparative and Physiological Psychology, 1974, 86, 51-55.

Nachman, M., Rauschenberger, J., \& Ashe, J. H. Studies of learned aversions using non-gustatory stimuli. In L. M. Barker, M. R. Best, \& M. Domjan (Eds.), Learning mechanisms in food selection. Waco, Tex: Baylor University Press, 1977.

Revusky, S., \& Garcia, J. Learned associations over long delays. In G. H. Bower \& J. T. Spence (Eds.), The psychology of learning and motivation: Advances in research and theory (Vol. 4). New York: Academic Press, 1970.

Rozin, P., \& Kalat, J. W. Specific hungers and poison avoidance as adaptive specializations of learning. Psychological Review, 1971, 78, 459-486.

Rudy, J. W., Iwens, J., \& Best, P. J. Pairing novel exteroceptive cues and illness reduces illness-induced taste-aversions. Journal of Experimental Psychology: Animal Behavior Processes, 1977, 3, 14-25.

Rudy, J. W., Rosenberg, L., \& Sandell, J. H. Disruption of a taste familiarity effect by novel exteroceptive stimulation. Journal of Experimental Psychology: Animal Behavior Processes, 1977, 3, 26-36.

Seligman, M. E. P. On the generality of the laws of learning. Psychological Review, 1970, 77, 400-418.

Seligman, M. E. P., \& Hager, J. L. Biological boundaries of learning. New York: Appleton-Century-Crofts, 1972.

She AfOR, P. J. "Pseudoconditioned" jaw movements of the rabbit reflect associations conditioned to contextual background cues. Journal of Experimental Psychology: Animal Behavior Processes, 1975, 104, 245-260.

Shettleworth, S. J. Food reinforcement and the organization of behaviour in golden hamsters. In R. A. Hinde \& J. StevensonHinde (Eds.), Constraints on learning. London: Academic Press, 1973.
(Received for publication February 25, 1980; revision accepted October 7,1980 .) 